\title{
Synthesis and Characterization of Carboxymethyl Cellulose from Sugarcane Bagasse
}

Saeid Alizadeh AsI, Mohammad Mousavi*and Mohsen Labbafi

Department of Food Science and Technology, Campus of Agricultural Engineering and Natural Resources, University of Tehran, Iran

\begin{abstract}
Various raw materials including plant biomass, bacteria, algae and the Tunicates (marine animals) have been used to produce cellulose. However, agricultural waste has rarely been utilized for this purpose. In this work, Sugarcane bagasse was used as raw material to produce cellulose. Cellulose was extracted from sugarcane bagasse through the elimination of lignin and hemicellulose. Cellulose was then converted to carboxymethyl cellulose (CMC $)$ by using sodium monochloroacet (SMCA) and various sodium hydroxide $(\mathrm{NaOH})$ concentrations. Fourier Transform Infrared Spectroscopy (FTIR) was applied to verify the effect of $\mathrm{NaOH}$ concentration on this property. The highest viscosity and degree of substitution (DS=0.78) were observed in 30 gr/100 $\mathrm{ml} \mathrm{NaOH}$ of carboxymethylation. Maximum tensile strength of the films produced at these conditions was $37.34 \mathrm{Mpa}$. The addition of a various amount of glycerol $(1 \mathrm{ml} / 100 \mathrm{ml}, 2 \mathrm{ml} / 100 \mathrm{ml}, 3 \mathrm{ml} / 100 \mathrm{ml})$ dramatically decreased the tensile strength. The highest level of water vapor permeability was also observed at the same $\mathrm{NaOH}$ concentration. Cellulose can be correctly extracted from sugarcane bagasse and converted to carboxymethyl cellulose. Based on the cellulose of the bagasse characteristic, proper amount of $\mathrm{NaOH}$ was found to get a high $\mathrm{DS}$. $\mathrm{CMC}_{\mathrm{b}}$ has considerable features for application on biodegradable coating materials
\end{abstract}

Keywords: Sugarcane bagasse; Carboxymethyl cellulose; Edible film; Mechanical properties

\section{Introduction}

Nowadays huge quantities of plant wastes are produced globally. Although they are the most abundant and renewable resource for organic substances attainable today [1,2], still considerable amounts of these materials are not used in proper way. Thus, the conversion of plant wastes into valuable products can be helpful in reduction of the environmental problems [3]. Plant wastes consists of more than $90 \%(\mathrm{w} / \mathrm{w})$ carbohydrate polymers which can be modified by both biochemical and chemical reactions to some products such as starch, cellulose, cotton linter, bagasse fiber etc. [4,5]. Sugarcane bagasse is a residue produced in large quantities every year by the sugar industries [6], and the most of this amount used as a fuel to supply the energy required for sugar mill [7]. Some reports reveal that bagasse is used as a raw material for industrial applications such as electricity generation, pulp and paper production, etc. New researches show the application of sugarcane bagasse to produce composites with bagasse linters [8]. However, the large quantities of sugar cane bagasse remain unused. Therefore, utilization of this huge agricultural waste for new applications has attracted growing interest because of their ecological and renewable characteristic. In general, each ton of sugarcane produces $280 \mathrm{~kg}$ bagasse. Sugar cane bagasse contains $40 \%$ to $50 \%$ cellulose (crystalline and amorphous structure), 25\% to 35\% hemicellulose (amorphous polymers usually composed of xylose, arabinose, galactose, glucose and mannose), $15 \%$ to $20 \%$ of lignin and the remainder lesser amounts of mineral, wax, and other compounds [9].

Cellulose is an important component for the application of new biomaterials obtained from agriculture wastes. Cellulose is usually found in the cell wall of plants and is generally associated with lignin and hemicellulose, which make it difficult to extract in pure form [10]. Cellulose is a high molecular weight and a linear homopolymer of repeating $\beta$-D-glucopyranosyl units joined by single oxygen atoms (acetal linkages) between the $\mathrm{C}-1$ of one pyranose ring and the $\mathrm{C}-4$ of the next ring, Because of their linearity and stereo regular nature, cellulose molecules associate over extended regions, forming polycrystalline, fibrous bundles. Large numbers of hydrogen bonds together hold crystalline regions. They are separated by, and connected to, amorphous regions. Cellulose is insoluble because, for to dissolve, most of these hydrogen bonds would have to be released at once. However, Cellulose through substitution can be converted into watersoluble gums $[11,12]$. Cellulose can be applied in various form, its original fibers (used in textile and paper) or its derivative forms such as methyl cellulose and carboxymethyl cellulose.

carboxymethyl cellulose is a linear, long-chain, water-soluble, anionic polysaccharide. Purified CMC is a white- to cream-colored, tasteless, odorless, powder $[13,14]$. Sodium carboxymethyl cellulose is formed when cellulose reacts with mono chloroacetic acid or its sodium salt under alkaline condition with presence of organic solvent, hydroxyl groups substituted by Sodium carboxymethyl groups in C2, C3 and C6 of glucose, which substitution slightly prevails at C2 position $[15,16]$. Carboxymethyl cellulose (CMC) is extensively used as a food gum. It has many applications in various industries such as food, pharmaceutics, detergent, lubricants, adhesives etc. [17-25]. However, Due to extensive use of CMC, many studies have been done to produce CMC from various resources such as durian rind [4], cotton linters [16], sugar beet pulp [26], cashew tree gum [27], Cavendish banana pseudo stem [28], sago waste [3], papaya peel [29], and Mimosa pigra peel [30]. Therefore, the purpose of this work was the production of carboxymethyl cellulose from bagasse $\left(\mathrm{CMC}_{\mathrm{b}}\right)$ and study the effect of $\mathrm{NaOH}$ concentration on Characteristics of CMC synthesized from sugarcane bagasse and evaluation of this film.

${ }^{*}$ Corresponding author: Mohammad Mousavi, Department of Food Science and Technology, Campus of Agricultural Engineering and Natural Resources, University of Tehran, P.O. Box 4111, Karaj 31587-77871, Iran, Tel: +982632248804; Fax: +98-2632249453; E-mail: Mousavi@ut.ac.ir

Received July 13, 2017; Accepted July 31, 2017; Published August 07, 2017

Citation: AsI SA, Mousavi M, Labbafi M (2017) Synthesis and Characterization of Carboxymethyl Cellulose from Sugarcane Bagasse. J Food Process Technol 8 : 687. doi: 10.4172/2157-7110.1000687

Copyright: (c) 2017 Asl SA, et al. This is an open-access article distributed under the terms of the Creative Commons Attribution License, which permits unrestricted use, distribution, and reproduction in any medium, provided the original author and source are credited. 


\section{Materials and Methods}

\section{Materials}

Required quantities of sugarcane bagasse was collected from the farms of Khuzestan, Iran. Sodium hydroxide, potassium hydroxide and glacial acetic acid were prepared from Merck Chemical Co. (Darmstadt, Germany). Ethanol and methanol were provided from the local market. Isopropanol and sodium mono chloroacetate were purchased from Daejung Co. (South Korea). Sodium chlorite $\left(\mathrm{NaClO}_{2}\right)$ used in the experiment was from Sigma-Aldrich, USA.

\section{Extraction of cellulose}

First of all, bagasse was milled and de-pitched, then the fiber was cooked at $370^{\circ} \mathrm{C}$ in digester prior to bleaching with Sodium hypochlorite and Chlorine gas and washing with KCL 5\%. After this process bagasse fiber with 70-80 of Degree of whiteness (Euro standard) was obtained. Additional bleaching on the samples was carried out in two steps; with sodium chlorite $3 \%$ and then $1 \%(1: 10)$ at $\mathrm{Ph}=3.8-4$ [31]. Elimination of hemicellulose from the pulp was then done with $10 \mathrm{~g} / 100 \mathrm{ml} \mathrm{KOH}$ $(1: 20)$ at $80^{\circ} \mathrm{C}$ for $2 \mathrm{~h}$ (after $12 \mathrm{~h}$ remaining in room temperature) after every step for elimination residual, pulp was washed with distilled water. Alpha-cellulose content was measured by following Equation 1 according to the TAPPI T $203 \mathrm{~cm}-99$ standard.

$$
\alpha-\text { cellulose }(\%)=\frac{w_{2}-w_{1}}{w_{1}} \times 100
$$

\section{Synthesis of carboxymethyl cellulose $\left(\mathrm{CMC}_{\mathrm{b}}\right)$ from cellulose of sugarcane bagasse}

The synthesis of Carboxymethyl cellulose followed the procedure described by Rachtanapun et al. [29]. Nine grams of Cellulose powder from sugarcane bagasse, $30 \mathrm{ml}$ of $\mathrm{NaOH}(20 \mathrm{~g} / 100 \mathrm{ml}, 30 \mathrm{~g} / 100 \mathrm{ml}$, $40 \mathrm{~g} / 100 \mathrm{ml}, 50 \mathrm{~g} / 100 \mathrm{ml}$ ) and $270 \mathrm{ml}$ of solvent (isopropanol, due to its good ability in cellulose etherification based on Pushpamalar et al. [3] study was stirred in the beaker and let stand for $30 \mathrm{~min}$ at ambient temperature. Then $10.8 \mathrm{~g}$ of sodium mono chloroacetate was added and mechanically stirred for $90 \mathrm{~min}$ in a beaker and covered with aluminum foil and keep in $55^{\circ} \mathrm{C}$ for $180 \mathrm{~min}$. During this time, the reaction continued and the slurry divided into two phases. The upper phase's discarded and sedimentary phases suspend in 70\% methanol $(100 \mathrm{ml})$ and neutralized using glacial acetic acid and then, filtered and washed five times with $70 \%$ ethanol $(300 \mathrm{ml})$ to remove undesirable salts. Afterward, it was washed again with absolute methanol and filtered. The obtained $\mathrm{CMC}_{\mathrm{b}}$ was dried at $55^{\circ} \mathrm{C}$ in an oven. The yield of $\mathrm{CMC}_{\mathrm{b}}$ was calculated by the following Equation 2:

$$
\text { Yieldof } C M C_{b}(\%)=\frac{\text { Weight of } C M C}{\text { Weight of cellulose }} \times 100
$$

\section{Degree of substitution (DS)}

DS value shows the average amount of hydroxyl group that was replaced by (sodium) Carboxymethyl group in the cellulose structure at $\mathrm{C} 2, \mathrm{C} 3$ and C6. The DS value of CMC from bagasse was measured by USP XXIII method described for Croscarmellose sodium, this method included 2 steps titration and residue on ignition.

\section{Film preparation}

Some quantities of powdered CMC from bagasse was dissolved in $100 \mathrm{ml}$ distilled water at $80^{\circ} \mathrm{C}$ and stirred. Mixing was done until a homogeneous solution obtained. $1 \mathrm{ml}, 2 \mathrm{ml}$ and $3 \mathrm{ml}$ of glycerol were added to $100 \mathrm{ml}$ of solution as a plasticizer. After obtaining a homogeneous solution, a film with a diameter of $10 \mathrm{~cm}(60 \mathrm{ml})$ was formed on glass plates by casting, then dried at $55^{\circ} \mathrm{C}$ within 24 hours.

\section{Thickness}

The thickness of the films was adjusted by the volume of film solution that cast on the plate (specific volume of solution poured on a plate with a fixed diameter) and measured by micrometers (model Mitutoyo, LIC.NO.689037, Japan). Measurements were done at ten different points on each sample and the average value was used to calculate mechanical properties.

\section{Color}

Colorimetry test was used to determine the color of samples with Chromameter CR-400 (japan). Three parameters which can be reached that in colorimeter is $\mathrm{L}$ (white $=100$, black $=0$ ), a (green $=-60$, red $=+60$ ) and $b$ (blue $=-60$, yellow $=+60$ ). For each sample, at least three replications were done.

\section{Mechanical properties}

Measuring some mechanical properties of films was performed using tensile tester (M350-10CT, Testometric Co., Ltd., Rochdale, and Lancashire, England). Film samples were cute in $1 \times 10 \mathrm{~cm}$ rectangles to be used as a test specimen, the samples preconditioned [32] at 53\% RH for 48 hours in a desiccator containing magnesium nitrate. The initial grip separation and cross-head speed were set at $20 \mathrm{~mm}$ and $1 \mathrm{~mm} /$ min, respectively. Tensile strength and strain at break for specimen obtained using the curves of stress-strain. All measurement was done in triplicate.

\section{Water vapor permeability}

Water vapor permeability of the $\mathrm{CMC}_{\mathrm{b}}$ films was performed based on modified ASTM (1995-method E96). According to this test, at first the films were cut into a circle (with $10 \mathrm{~mm}$ diameter), then placed on the glass cells with a specific diameter, and sealing completely with paraffin wax (anhydrous calcium chloride was poured into a glass cell that provides zero percent relative humidity). The glasses weight and was kept in a desiccator preserved at $75 \% \mathrm{RH}$ with saturated sodium chloride at $25^{\circ} \mathrm{C}$. Due to the Moisture differences on both side of the film (vapor pressure gradient), water vapor transmitted through the film specimen and absorbed by desiccant, evaluations were determined by measuring the weight gain. Changes in weight of the cells were recorded and plotted as a function of time. The slope of each line calculated using linear regression $\left(r^{2}>0.99\right)$. Water vapor transmission rate (WVTR) $\left(\mathrm{g} / \mathrm{sm}^{2}\right.$ calculated by Equation 3. And finally, the film permeability to water vapor (WVP) was calculated using the following equation (Equation 4$)$ :

$$
\begin{gathered}
W V T R=\frac{\text { slope }(\mathrm{g} / \mathrm{s})}{\text { surfacearea }\left(\mathrm{m}^{2}\right)} \\
W V P=\left[\frac{W V T R}{S\left(R_{2}-R_{1}\right)}\right] \times D
\end{gathered}
$$

Where $\mathrm{S}$ is saturation vapor pressure $(\mathrm{Pa})$ at the test temperature $\left(25^{\circ} \mathrm{C}\right) ; \mathrm{R}_{1}$ relative humidity at the desiccator; $\mathrm{R}_{2}$ relative humidity inside the cell and D film thickness (m).

\section{Viscosity}

The viscosity of CMC samples was measured using rotational viscometer (LV model, Brookfield with ULA spindle). Samples were 
prepared by dissolved of $1 \mathrm{gr}$ CMC in $100 \mathrm{ml}$ distilled water followed by vigorous mixing, then the solution was standing for a while to remove air bubbles. The viscosity of samples was measured by the ASTM D1439-94 at different temperature $\left(30^{\circ} \mathrm{C}, 40^{\circ} \mathrm{C}\right.$, and $\left.50^{\circ} \mathrm{C}\right)$. All measurements were performed in triplicate.

\section{FTIR}

The Functional groups of carboxymethyl cellulose were investigated using infrared spectroscopy spectrum (EQUINOX 55, BRUKER Germany). Pellets were made by $\mathrm{CMC}_{\mathrm{b}}$ with $\mathrm{KBr}$. Transmission levels were measured for wave numbers of 4000-400 $\mathrm{cm}^{-1}$.

\section{Statistical analysis}

The collected data were analyzed by ANOVA and compared by Duncan's multiple range test ( $\mathrm{p} \leq 0.05)$ with SPSS 18 .

\section{Results}

\section{a-cellulose}

The alpha cellulose content was about $81 \% \pm 2 \%$, which indicates sufficient purification of the sample from all impurities.

\section{Degree of substitution (DS)}

The Degree of Substitution (DS) is the average number of hydroxyl groups in the cellulose structure substituted by carboxymethyl or sodium carboxymethyl groups at the carbon 2, 3 and 6. Each anhydroglucose ( $\beta$-glucopyranose) unit has three reactive (hydroxyl) groups so theoretically DS value can be in the range from zero (cellulose itself) to three (fully substituted cellulose). In general, the DS of carboxymethyl cellulose obtained by alkalization reaction of cellulose with sodium mono chloroacetate was in the range of 0.4-1.3. CMC is fully soluble at DS above 0.4 and hydro affinity of CMC increases with increasing DS, while this polymer is swellable but insoluble below 0.4 [33]. The DS of CMC obtained in this work was in the expected range of $0.45-0.78$, as figured in Figure 1A. As presented in this figure, the $\mathrm{DS}$ of $\mathrm{CMC}_{\mathrm{b}}$ increased by adding $\mathrm{NaOH}$ concentration up to $30 \%$, which shows the efficient concentration of alkali reagent in carboxymethylation procedure. Carboxymethylation of cellulose takes place by three simultaneously reaction as shown in equations 5-7:

$$
\begin{aligned}
\mathrm{Cell}-\mathrm{OH}+\mathrm{NaOH} \rightarrow & \text { Cell-OH. } \mathrm{NaOH} \\
& \text { Alkali cellulose }
\end{aligned}
$$

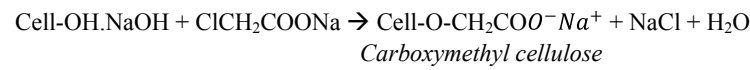

$$
\mathrm{NaOH}+\mathrm{Cl}-\mathrm{CH}_{2} \mathrm{COONa} \rightarrow \underset{\text { Sodium glycolate }}{\mathrm{HO}-\mathrm{CH}_{2} \mathrm{COONa}+\mathrm{NaCl}}
$$

According to Equation 5, Cellulose chains are swollen by Sodium hydroxide as an alkaline reagent (alkali cellulose), which provided the ability of substitution by sodium carboxymethyl groups in cellulose units. (Expose reactive site of anhydroglucose in compact cellulose chain to substitute by ether groups). The role of the solvent in the cellulose etherification is to provide miscibility and accessibility of the etherifying reagent (NaMCA) to the reaction centers of the cellulose chain rather than glycolate formation. Sodium mono chloroacetate (NaMCA) as an etherifying group participate in reaction and provide sodium carboxymethyl groups for substitution at C2, C3 and C6. As shown in Figure 1A, DS value augmented by adding $\mathrm{NaOH}$ concentration up to a maximum DS of 0.78 for $30 \% \mathrm{NaOH}$. At this level of $\mathrm{NaOH}$ concentration cellulose etherification (Equation 6) is
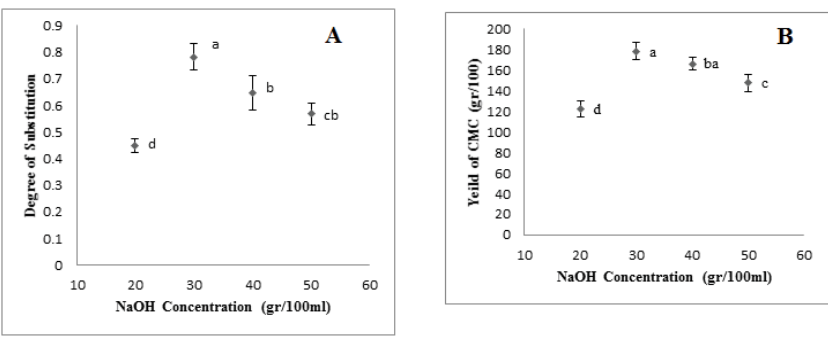

Figure 1: Effect of $\mathrm{NaOH}$ concentration on DS $(A)$ and the yield of $\mathrm{CMC}(\mathrm{B})$ from sugarcane bagasse.

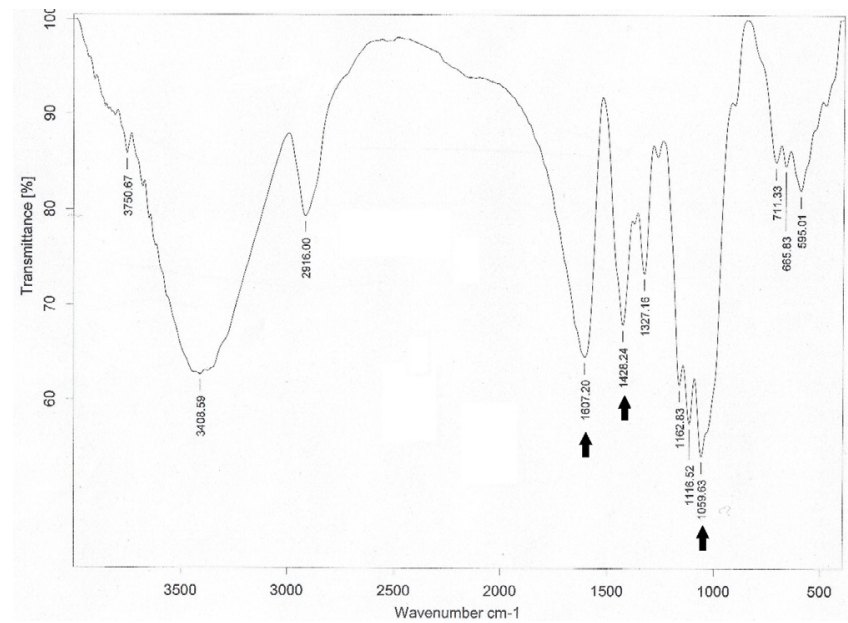

Figure 2: FTIR spectra of CMC made from cellulose of sugarcane bagasse with DS of 0.78 which was synthesized using $30 \% \mathrm{NaOH}$ (the related peaks with substituted groups are marked with arrows).

predominating which produces $\mathrm{CMC}_{\mathrm{b}}$ as a final product. Above $30 \%$ $\mathrm{NaOH}$ the DS value decreased. The reason for this observation is that an undesired side reaction happened which dominated the $\mathrm{CMC}_{\mathrm{b}}$ production. Sodium glycolate was the product of such undesired reaction. With further increasing of $\mathrm{NaOH}$ concentration, more reduction in DS value was observed. It can be explained by degradation effect of high concentration of alkali reagent on CMC polymer chains. It must be noticed that DS value is affected by cellulose source. Crystallinity and regularity of cellulose structure according to its origin and considering the feasibility of substitution is more happened in an amorphous part of the cellulose structure $[34,35]$. Figure 1B shows the $\mathrm{CMC}_{\mathrm{b}}$ yields from different experiments which indicated similarity with DS results. These results were in accordance with similar findings by several researchers.

\section{FTIR}

Fourier Transform Infrared Spectroscopy (FTIR) indicates chemical changes in the polymer structure. Cellulose and carboxymethyl have similar functional groups with same absorption bands in FTIR such as hydroxyl groups (-OH stretching) at $3200-3600 \mathrm{~cm}^{-1}$, hydrocarbon groups (- $\mathrm{CH}_{2}$ scissoring) at $1450 \mathrm{~cm}^{-1}$, carbonyl groups $(\mathrm{C}=\mathrm{O}$ stretching) at $1600 \mathrm{~cm}^{-1}$ and ether groups (-O-) at $1000-1200 \mathrm{~cm}^{-1}$, also $\mathrm{C}-\mathrm{H}$ stretching vibration at $3000 \mathrm{~cm}^{-1}$ [36]. Cellulose etherification with $\mathrm{NaCMA}$ causes the $\mathrm{OH}$ groups in cellulose replaced with $\mathrm{CH}_{2} \mathrm{COONa}$, which causes changes in the absorption spectrum of related bands. This lead $\mathrm{OH}$ groups to weaker peak and strengths or creates a new peak. However, from Figure 2, the differences can be observed in $\mathrm{CMC}_{\mathrm{b}}$ 
absorption bonds, at 1059, 1426 and 1607 absorption bands which are relevant to-O-, $\mathrm{CH}_{2}$ - and -COO, respectively. Pecsok [37] reported that the broadband at $1600-1640 \mathrm{~cm}^{-1}$ and $1400-1450 \mathrm{~cm}^{-1}$ is due to the carboxyl and its salts groups, which is confirmed substitution of carboxymethyl groups in cellulose structure. This peak doesn't exist in the FTIR spectra of cellulose from bagasse obtained in previous studies.

\section{Viscosity}

The viscosity of a solution is a measure of its resistance to gradual deformation by shear stress, which is due to intermolecular cohesive forces [37]. These forces are affected by some factors (CMC concentration, temperature, DS). Figure 3 shows the effect of $\mathrm{NaOH}$ concentration and temperature on viscosity of $\mathrm{CMC}_{\mathrm{b}}$ solution. This figure indicates, as expected, the viscosity of samples decreases with increasing temperature. It can be explained by the fact that, during the heating to raising the temperature the energy of the molecules and molecular movement increased so intermolecular distances increase, which in turn, decreasing cohesive forces between molecules and causing lower viscosity. The viscosity of $\mathrm{CMC}_{\mathrm{b}}$ samples increased with $\mathrm{NaOH}$ concentration (20\% to $30 \%)$ at the constant temperature due to the presence of greater hydrophilic groups in polymer structure induced by greater DS, which gives more ability to the polymer to immobilize water in the aqueous system. As far as $\mathrm{NaOH}$ concentration raised above $30 \%$, the viscosity fell down. This observation can be explained by decreasing of DS that provides less hydrophilic groups thereby ability of the polymer to bonding between water molecules reduced. Degradation effect of $\mathrm{NaOH}$ at a higher concentration on polymer chain also causes further declining in viscosity.

\section{Water vapor permeability}

Water Vapor Transmission Rate (WVTR) and Water Vapor Permeability (WVP) of the films obtained from $\mathrm{CMC}_{\mathrm{b}}$ with different concentrations of sodium hydroxide is shown in Table 1 . As tabulated,

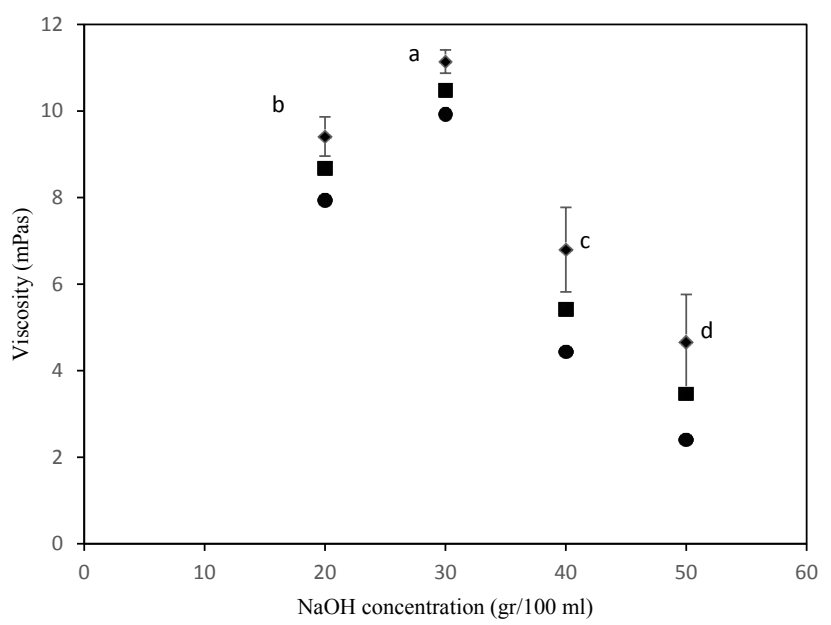

Figure 3: Effect of various $\mathrm{NaOH}$ concentration on viscosity of $\mathrm{CMC}$ from bagasse at different temperature $\left(30^{\circ} \mathrm{C}, 40^{\circ} \mathrm{C}, 50^{\circ} \mathrm{C}\right)$.

\begin{tabular}{|c|c|c|}
\hline Film type & WVP $(\mathrm{g} / \mathrm{msPa}) \times 10^{-10}$ & WVTR $\left(\mathrm{g} / \mathrm{s} . \mathrm{m}^{2}\right) \times 10^{-2}$ \\
\hline $\mathrm{CMC}_{\mathrm{b}}-20 \mathrm{gr} / 100 \mathrm{ml} \mathrm{NaOH}$ & $6.9632 \pm 0.472^{c}$ & $1.0477 \pm 0.071^{\mathrm{c}}$ \\
\hline $\mathrm{CMC}_{\mathrm{b}}-30 \mathrm{gr} / 100 \mathrm{ml} \mathrm{NaOH}$ & $11.0795 \pm 0.217^{a}$ & $1.5025 \pm 0.031^{a}$ \\
\hline $\mathrm{CMC}_{\mathrm{b}}-40 \mathrm{gr} / 100 \mathrm{ml} \mathrm{NaOH}$ & $9.4524 \pm 0.121^{\mathrm{b}}$ & $1.3510 \pm 0.016^{b}$ \\
\hline $\mathrm{CMC}_{\mathrm{b}}-50 \mathrm{gr} / 100 \mathrm{ml} \mathrm{NaOH}$ & $9.5868 \pm 0.094^{b}$ & $1.3270 \pm 0.013^{b}$ \\
\hline
\end{tabular}

Table 1: Water vapor transmission rate (WVTR) of $\mathrm{CMC}_{\mathrm{b}}$ films synthesized with various $\mathrm{NaOH}$ concentrations at $25^{\circ} \mathrm{C}, 75 \% \mathrm{RH}$

\begin{tabular}{|c|c|c|c|}
\hline Films type & $\mathbf{a}^{*}$ & $\mathbf{b}^{*}$ & $\mathbf{L}^{*}$ \\
\hline CMCb-20\% NaOH & $-0.595 \pm 0.12^{\mathrm{a}}$ & $5.35 \pm 1.87^{\mathrm{b}}$ & $58.465 \pm 10.98^{\mathrm{a}}$ \\
\hline $\mathrm{CMCb}-30 \% \mathrm{NaOH}$ & $-0.685 \pm 0.06^{\mathrm{a}}$ & $4.195 \pm 0.66^{\mathrm{b}}$ & $59.755 \pm 8.48^{\mathrm{a}}$ \\
\hline $\mathrm{CMCb}-40 \% \mathrm{NaOH}$ & $-0.34 \pm 0.03^{\mathrm{a}}$ & $3.295 \pm 0.62^{\mathrm{cb}}$ & $42.795 \pm 1.27^{\mathrm{a}}$ \\
\hline $\mathrm{CMCb}-50 \% \mathrm{NaOH}$ & $-0.52 \pm 0.04^{\mathrm{a}}$ & $6.845 \pm 0.33^{\mathrm{ab}}$ & $57.24 \pm 1.7^{\mathrm{a}}$ \\
\hline
\end{tabular}

Table 2: Color values of cellulose and $\mathrm{CMC}$ synthesized with various $\mathrm{NaOH}$ concentrations.

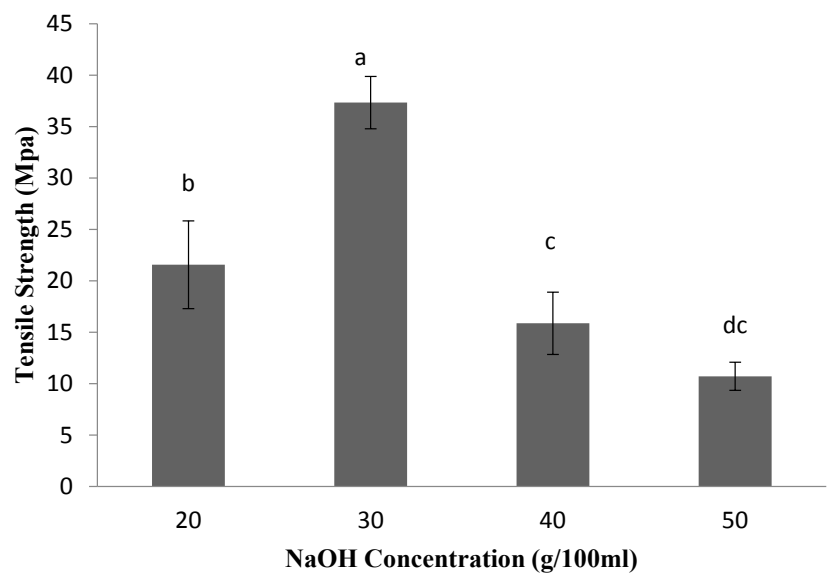

Figure 4: Tensile strength of CMC films.

when $\mathrm{NaOH}$ concentration increases, water vapor transmission rate significantly changes, and the highest WVP and WVTR values were observed for the films made with $30 \% \mathrm{NaOH}$. The Same trend was observed for DS of $\mathrm{CMC}_{\mathrm{b}}$ meaning that higher DS values provided the polymer with greater hydrophilic groups which facilitate water molecules to easily pass through the films by dissolution-diffusion mechanism. It is obvious from different literatures that water vapor transmission rate through hydrophilic films depends on diffusivity and solubility of water molecules in the films Matrix [38,39]. In general, polymer polarities increased by conversion of cellulose to carboxymethyl cellulose also causes crystallinity reduction and changes in the granular morphology [40]. However, it can be observed from Table 2 that WVP of films with higher $\mathrm{NaOH}$ concentration $(40 \%, 50 \%)$ reduced due to the reduction of hydrophilicity of films by declining polarity of the polymer.

\section{Color}

The result of color measurement of $\mathrm{CMC}_{\mathrm{b}}$ films specimen is shown in Table 2. According to the values shown in this table, carboxymethyl cellulose from bagasse with different concentration of $\mathrm{NaOH}$ gives lighter, yellowish and slightly viridescent films. As can be seen, yellowness of samples decreased with increasing $\mathrm{NaOH}$ concentration up to $40 \%$. It is probably due to the competitive reaction (Equations 2 and 3) to produce CMC or sodium glycolate. Beyond $40 \% \mathrm{NaOH}$ yellowness increased which is most likely due to the intrinsic color of $\mathrm{NaOH}$ solution.

\section{Mechanical properties}

The results prove the effect of different concentrations of sodium hydroxide on mechanical properties of films. The tensile strength (TS) of film samples of carboxymethyl cellulose obtained under different conditions is given in the Figure 4. The TS of films increased with increasing $\mathrm{NaOH}$ concentration and maximum TS (37.34 Mpa) was observed in $30 \% \mathrm{NaOH}$, while TS decreased at higher concentration. With increasing the DS value due to the placement of more sodium 
carboxymethyl groups in cellulose structure, the polarity of the polymer chains increased which promoted more intermolecular bonds between the polymer chains. On the other hand, at higher concentration of $\mathrm{NaOH}$ due to the formation of sodium glycolate as a reaction byproduct during $\mathrm{CMC}$ production (decreasing in polymer chains ionic characteristic), TS decreased. TS reduction was intense with degradation effect of high concentration of $\mathrm{NaOH}$ on polymer chains. Decreasing in the $\mathrm{CMC}$ content at high $\mathrm{NaOH}$ concentration provides a reduction in intermolecular forces [41].

\section{Discussion}

The effect of various $\mathrm{NaOH}$ concentrations on the percent elongation at break (EB) of $\mathrm{CMC}_{\mathrm{b}}$ films is depicted in Figure 5 As can be observed, the $\mathrm{EB}$ of $\mathrm{CMC}_{\mathrm{b}}$ film increased with increasing $\mathrm{NaOH}$ concentration, beyond the $40 \% \mathrm{NaOH}$ concentration the $\mathrm{EB}$ of films dropped. This increase can be attributed to the fact that at high concentration of $\mathrm{NaOH}$ polymer chains get more swelled that declined the crystallinity and increase the flexibility of cellulose structure. Under higher concentration of $\mathrm{NaOH}$, due to hydrolysis reaction on polymer chains, the flexibility of $\mathrm{CMC}_{\mathrm{b}}$ films decreased. The mechanical properties of $\mathrm{CMC}_{\mathrm{b}}$ films after applying plasticizer were also studied. Glycerol, as an external plasticizer, was added to $\mathrm{CMC}_{\mathrm{b}}$ film in various amounts to improve the mechanical properties before casting. This was applied only to $\mathrm{CMC}_{\mathrm{b}}$ films with $30 \% \mathrm{NaOH}$ (with maximum TS). The results (Figure 6) showed that adding glycerol concentration lowers the TS of $\mathrm{CMC}_{\mathrm{b}}$ films. Glycerol lessens the internal hydrogen bonds between polymer chains which effect on film resistance under tension. On the other side, the $\mathrm{EB}$ of $\mathrm{CMC}_{\mathrm{b}}$ films increased at higher glycerol content. Glycerol positions between polymer chains and prevent the formation of further hydrogen bonds and reduce the intermolecular forces, thereby the chains are able to move and flexibility of them increased. Similar results have been reported previously.

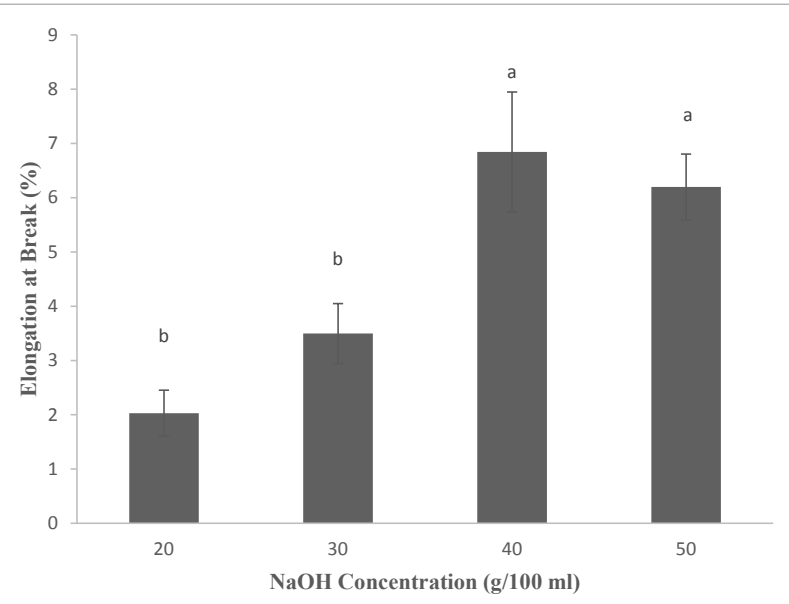

Figure 5: Elongation at break CMC films.
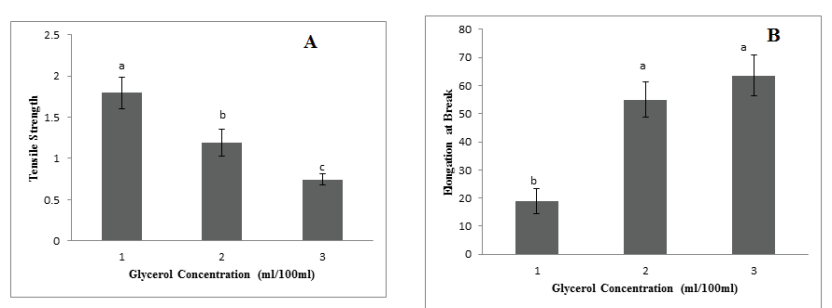

Figure 6: The TS (A) and The $\mathrm{EB}(\mathrm{B})$ of $\mathrm{CMC}_{\mathrm{b}}-30 \% \mathrm{NaOH}$ films with various amount of glycerol (1,2 and $3 \%$ ).

\section{Conclusion}

Sugarcane bagasse was properly used to extract cellulose and synthesis of carboxymethyl cellulose. The results showed maximum DS of $\mathrm{CMC}_{\mathrm{b}}(0.78)$ at $30 \%$ of $\mathrm{NaOH}$ concentration. The viscosity, water vapor permeability, and mechanical properties are dependent to DS of $\mathrm{CMC}_{\mathrm{b}}$. Based on water vapor permeability and mechanical properties of $\mathrm{CMC}_{\mathrm{b}}$ films, the possibility of its application on biodegradable coating materials is envisaged. Carboxymethylation of cellulose from bagasse was affected by various $\mathrm{NaOH}$ concentration, and crystallinity of cellulose sources is important for finding an appropriate concentration of $\mathrm{NaOH}$. Carboxymethyl cellulose is one of most widely used cellulose derivatives in various industries like food, pharmaceutical, detergent, paper-making, oil drilling and Textile. Therefore, considering the methods that modified cellulose as cellulose derivatives, can help us to overcome environmental problems of agricultural waste (bagasse), which produced in large scale, and economical ways to use sugarcane bagasse.

\section{Acknowledgements}

The authors gratefully acknowledge the financial support from the Center of excellence for the application of novel technologies in functional foods and beverages of the University of Tehran.

\section{References}

1. Mandal A, Chakrabarty D (2011) Isolation of nanocellulose from waste sugarcane bagasse (SCB) and its characterization. J Carbpol 86: 1291-1299.

2. Shaikh HM, Pandare KV, Nair G, Varma AJ (2009) Utilization of sugarcane bagasse cellulose for producing cellulose acetates: Novel use of residual hemicellulose as plasticizer. J Carbpol 76: 23-29.

3. Pushpamalar V, Langford S, Ahmad M, Lim YY (2006) Optimization of reaction conditions for preparing carboxymethyl cellulose from sago waste. J Carbpo 64: 312-318.

4. Rachtanapun P, Luangkamin S, Tanprasert K Suriyatem R (2012) Carboxymethyl cellulose film from durian rind. Food Sci Technol 48: 52-58.

5. Viera RG, Rodrigues Filho G, De Assunção RM, Meireles CdS, Vieira JG, et al. (2007) Synthesis and characterization of methylcellulose from sugar cane bagasse cellulose. J Carbpol 67: 182-189.

6. Chandel AK, Da Silva SS, Carvalho W, Singh OV (2012) Sugarcane bagasse and leaves: Foreseeable biomass of biofuel and bio $\square$ products. J Chem Technol Biotechnol 87: 11-20

7. Sun J, Sun X, Zhao H, Sun R (2004) Isolation and characterization of cellulose from sugarcane bagasse. Polymer Degrad Stab 84: 331-339.

8. Loh Y, Sujan D, Rahman M, Das C (2013) Sugarcane bagasse: The future composite material: A literature review. Res Conserv Recycle 75: 14-22.

9. Sun J, Sun X, Sun R, Su Y (2004) Fractional extraction and structural characterization of sugarcane bagasse hemicelluloses. J Carbpol 56: 195-204.

10. Thomas G, Paquita E, Thomas J (2002) Cellulose ethers: Encyclopedia of polymer science and technology. Wiley online, New York, USA.

11. Damodaran S, Parkin KL, Fennema OR (2007) Fennema's food chemistry. CRC press, USA.

12. Yaşar F, Toğrul H, Arslan N (2007) Flow properties of cellulose and carboxymethyl cellulose from orange peel. J Food Eng 81: 187-199.

13. Hattori K, Abe E, Yoshida T, Cuculo JA (2004) New solvents for cellulose: II Ethylenediamine/thiocyanate salt system. Polymer J 36: 123-130.

14. Keller J (1984) Sodium carboxymethylcellulose (CMC). New York state agricultural experiment station special report, USA 53: 9-19.

15. Heinze T, Pfeiffer K (1999) Studies on the synthesis and characterization of carboxymethylcellulose. Die Angewandte Makromolekulare Chemie 266: 37-45.

16. Xiquan L, Tingzhu Q, Shaoqui Q (1990) Kinetics of the carboxymethylation of cellulose in the isopropyl alcohol system. Acta Polymerica 41: 220-222. 
Citation: AsI SA, Mousavi M, Labbafi M (2017) Synthesis and Characterization of Carboxymethyl Cellulose from Sugarcane Bagasse. J Food Process Technol 8: 687. doi: 10.4172/2157-7110.1000687

17. Boursier B, Bussiere G, Devos F, Hughette M (1985) Sugarless hard candy. Google Patents.

18. Charpentier D, Mocanu G, Carpov A, Chapelle S, Merle L, et al. (1997) New hydrophobically modified carboxymethylcellulose derivatives. J Carbpol 33: 177-186.

19. Gayrish G, Saychenko N, Kozlova Y, Melanichenko I, Liptuga N (1989) Carboxymethylcellulose urea resin blend adhesives. SU Patent 87: 4293505

20. Koyama T (1988) Permanent waves of hair with carboxymethyl cellulose salts Google Patents.

21. Lee M, Torras MF (1993) Pesticidal aqueous cellulose ether solutions. WO Patent: 9313657

22. Leupin J, Gosselink E (1999) Laundry detergent compositions with cellulosic polymers as additives for improving appearance and integrity of laundered fabrics. WO Patent: 9914295.

23. Rachtanapun P, Thanakkasaranee S, Soonthornampai S (2008) Application of carboxymethylcellulose from papaya peel for mango (Mangifera Indica L.) 'Namdokmai'coating. Agricultural Sci J 39: 74-82.

24. Sánchez E, Sanz V, Bou E, Monfort E (1999) Carboxymethlycellulose used in ceramic glazes (Part III): Influence of CMC characteristics on glaze slip and consolidated glaze layer properties. CFI: Ceramic forum international.

25. Soper J (1991) Oily, free-flowing, microcapsules, comprising grafted and crosslinked gelatin: CMC wall material. US Patent: 89,401,189.

26. Toğrul H, Arslan N (2003) Production of carboxymethyl cellulose from sugar beet pulp cellulose and rheological behaviour of carboxymethyl cellulose. $J$ Carbpol 54: 73-82.

27. Silva DA, De Paula RC, Feitosa JP, De Brito AC, Maciel JS, et al. (2004) Carboxymethylation of cashew tree exudate polysaccharide. J Carbpol 58 : 163-171.

28. Adinugraha MP, Marseno DW (2005) Synthesis and characterization of sodium carboxymethylcellulose from cavendish banana pseudo stem (Musa cavendishii LAMBERT). J Carbpol 62: 164-169.

29. Rachtanapun P, Kumthai S, Yakee N, Uthaiyod R (2007) Production of carboxymethylcellulose (CMC) film from papaya peels and its mechanical properties. The Proceedings of the $45^{\text {th }}$ Kasetsart University Annual Conference, Kasetsart University, Kasetsart, Thailand.
30. Rachtanapun P, Rattanapanone N (2011) Synthesis and characterization of carboxymethyl cellulose powder and films from Mimosa pigra. J Appl Polymer Sci 122: 3218-3226.

31. Mali S, Grossmann MVE, García MA, Martino MN, Zaritzky NE (2004) Barrier, mechanical and optical properties of plasticized yam starch films. J Carbpol 56: $129-135$

32. Yousefi H, Nishino T, Faezipour M, Ebrahimi G, Shakeri A (2011) Direct fabrication of all-cellulose nanocomposite from cellulose microfibers using ionic liquid-based nanowelding. Biomacromolecule 12: 4080-4085.

33. Waring M, Parsons D (2001) Physico-chemical characterization of carboxymethylated spun cellulose fibres. Biomaterial 22: 903-912.

34. Brown Jr RM (1992) Emerging technologies and future prospects for industrialization of microbially derived cellulose. Harnessing Biotechnology for the $21^{\text {st }}$ Century.

35. Manguiat LS, Sabularse V, Sabularse DC (2001) Development of carboxymethylcellulose from nata de coco. Asian J Sci Technol Develop 18 85-94

36. Kondo T (1997) The assignment of IR absorption bands due to free hydroxy groups in cellulose. Cellulose 4: 281-292.

37. Pecsok RL (1976) Modern methods of chemical analysis, John Wiley \& Sons, USA.

38. El-Ghzaoui A, Trompette JL, Cassanas G, Bardet L, Fabregue E (2001) Comparative rheological behavior of some cellulosic ether derivatives. Langmuir 17: 1453-1456.

39. Gontard N, Guilbert S (1993) Biopackaging: Technology and properties of edible and/or biodegradable material of agricultural origin. Food Packag Preserv, Westport Connecticut, USA.

40. Li Y, Shoemaker CF, Ma J, Shen X, Zhong F (2008) Paste viscosity of rice starches of different amylose content and carboxymethylcellulose formed by dry heating and the physical properties of their films. Food Chem 109: 616-623.

41. Barai B, Singhal R, Kulkarni P (1997) Optimization of a process for preparing carboxymethyl cellulose from water hyacinth (Eichornia crassipes). J Carbpol 32: $229-231$ 